\title{
A novel marine phosphorus record from Lower Jurassic belemnites
}

\author{
AILSA C. ROPER ${ }^{1}$, CLEMENS ULLMANN ${ }^{2,3}$, CRISPIN T.S. \\ LITTLE $^{4}$, SIMON W. POULTON ${ }^{4}$, PAUL B. WIGNALL ${ }^{4}$, \\ TIANCHEN HE ${ }^{4}$, BENJAMIN J. W. MILLS ${ }^{4}$ AND ROBERT J \\ NEWTON $^{4}$ \\ ${ }^{1}$ University of Leeds \\ ${ }^{2}$ University of Oxford \\ ${ }^{3}$ University of Exeter \\ ${ }^{4}$ School of Earth and Environment, University of Leeds \\ Presenting Author: eeacro@leeds.ac.uk
}

Phosphorus is generally considered the ultimate limiting nutrient on geological timescales, and is a potential driver of past intervals of marine anoxia/euxinia. Despite its importance, obtaining direct information on spatial and temporal variations in marine phosphorus concentrations has proved challenging. Recent work has demonstrated the potential for calcium carbonate-associated phosphorus in corals to record watercolumn phosphorus $[1,2]$. Building on this approach, we are investigating the use of other calcitic fossils as a proxy for water column phosphorus concentration, focussing on belemnites, an extinct group of nektic molluscs.

We have developed a method to quantify belemnite phosphorus and have applied this method to samples from the upper Sinemurian to Toarcian in the Lower Jurassic. This period contains several major climatic and environmental events of interest, including an icehouse event during the Pliensbachian, a warming event during the Toarcian which coincided with widespread reduced oxygen conditions on the epicontinental seaways (the Toarcian Ocean Anoxic Event [TOAE]), and a second order mass extinction event (the Early Toarcian Mass Extinction).

We have also developed a biogeochemical model, adapted from the COPSE model [3], to investigate changes in marine phosphorus, nitrogen, and oxygen concentrations through time. Unlike previous versions of the COPSE model, this version contains separate boxes for processes occurring in the shelf and deep oceans. Shelf oceans have played an important role in marine nutrient cycles throughout Earth's history, particularly in the Lower Jurassic when the European Epicontinental Sea (EES) exhibited widespread anoxia.

We will present $\mathrm{P} / \mathrm{Ca}$ results for Sinemurian to Toarcian belemnites from a number of sites in the EES, which show similar trends in belemnite phosphorus concentrations, including a sharp peak during the TOAE. We will also describe the development and initial results of the biogeochemical modelling.

[1] LaVigne, Field, Anagnostou, Grottoli, Wellington, \& Sherrell (2008), Geophysical Research Letters 35.

[2] LaVigne, Matthews, Grottoli, Cobb, Anagnostou, Cabioch \& Sherrell (2010), Geochimica et Cosmochimica Acta 74, 1282 1293

[3] Bergman, Lenton \& Watson (2004), American Journal of Science 304(5), 397-437 